\title{
Software analysis for the hydraulic calculation of storm-water drainage gravity-flow networks comprising electronic model development
}

\author{
Grigory Gromov ${ }^{*}$, Andrey Ten, and Darya Khudyakova \\ Moscow State University of Civil Engineering, Yaroslavskoe shosse, 26, Moscow, 129337, Russia
}

\begin{abstract}
In accordance with the Resolution of the Russian Federation Government N 782 "Concerning the Development of Water Supply and Wastewater Disposal Systems", the development of surface run-off disposal systems comprising the electronic model, is a topical issue for the design and operation of wastewater disposal systems for the Russian settlements. In this context, the software used must provide making the hydraulic calculations for the gravity-flow systems of storm-water drainage networks. [1].

The analysis of Russian software [2-4] revealed the impossibility to develop electronic models and to make hydraulic calculations for the gravity-flow networks of storm-water drainage systems. In this connection, the possibilities offered by the foreign software products, which electronic models make it possible to carry out the required hydraulic calculations and to design surface run-off disposal systems, were studied $[5,6]$. This article contains the analysis of the European document BS EN 752:2008 [7] with regard to determining the flow of surface (storm-water) run-off, as well as the calculations made by the authors, which reveal that foreign software products are not applicable in Russia. Nevertheless, for the development of the electronic model for the hydraulic calculation of a storm-water drainage system, some mathematical relationship was found that most adequately characterizes the type of surface run-off hydrograph, most typically occurring on the territory of the Russian Federation in cases of atmospheric precipitation fallout. This relationship comprises the application of the RTK hydrograph method.
\end{abstract}

\section{Introduction}

The analysis of technical literature [7-9] revealed that the determination of surface run-off rate for run-off hydrograph modeling has several directions. In general, hydrographs are graphical presentations of storm run-off rate variations in $Q(t)$ time and they are used for finding the peak flows.

There are the following approaches to the determination of surface run-off flow: the construction of hydrological (infiltration) models and empirical models.

\footnotetext{
Corresponding author: stquests@gmail.com
} 
The hydrological (infiltration) model is based on several calculation methods: SCS method, rational method, Green-Ampt equation and Horton equation.

\section{Methods}

As to the empirical model, it comprises the following: R-factor, unit hydrograph; regression method and RTK method. Since the development of empirical models is based on the construction of surface run-off hydrographs, let us dwell on them in more detail.

R-factor method. This method is based on the assumption that the percentage of precipitation entering a storm-water drainage system is relatively constant during rather a long period and it is described in the following way:

$$
V=R \cdot V_{p}
$$

where $V$ - the volume of inflow/infiltration into the sewer $\left(f t^{3}, m^{3}\right) ; V_{p}$ precipitation volume $\left(f t^{3}, m^{3}\right) ; R$ - the percentage of precipitation that enters the surface run-off disposal system.

The total design flow (RDII) is a surface run-off flow summary curve that is designed for determining the storm-water design flow rates with respect to time; it is closely linked to the condition of soil and it has an impact on the shape of a rainfall graph. If the soil is oversaturated with water before the beginning of a rainfall, the $\mathrm{R}$ value for this event will be high. When the soil is dry, $\mathrm{R}$ will have lower values. It may be a useful instrument for the comparison of water catchment areas that receive the rainfalls of similar characteristics and have identical initial climatic conditions.

Unit hydrograph. The concept of a unit hydrograph was introduced by Sherman in 1932. The transformation of unit hydrographs is performed either through the application of special methods or is based on obtained measurements.

Meanwhile, Chinks and Mays in 1996 stressed that precipitation duration and intensity are not equal. That is why a precipitation fallout, being an event occurring with the course of time, should be subdivided into several intervals and the obtained hydrographs should be superimposed on one another in order to get the final one as a result of it.

Regression method. In most cases for surface run-off rate determination, the method of linear regression was applied for every time interval. It may be formulated using the following equation:

$$
Q(t)=\sum_{i=0}^{t} C_{i} P_{t-i}
$$

Where $Q(t)$ - surface run-off $\operatorname{rate}\left(f^{3} / \mathrm{sec}, \mathrm{m}^{3} / \mathrm{sec}\right) ; P_{t-i}$ - precipitation in the $i$-th time interval before the $t$ time (inch, $\mathrm{mm}$ ); $C_{i}$ - regression coefficient, relating the surface run-off to precipitation in the $i$-th time interval before the $t$ time.

The above-mentioned unit hydrograph method may be regarded as a particular case of regression method. The advantage of this method is the possibility to construct the surface run-off hydrographs for the models where the intensity varies with time.

The RTK hydrograph method (run-off hydrograph). The analysis of literature sources [7-9] revealed that the empirical model of a unit hydrograph most adequately describes the process of a rainfall and the kind of typical run-off hydrograph most frequently observed on the territory of the Russian Federation. Its development is carried out through the application of Snider method [8], based on the development of unit hydrographs. Figure 1 is the graphical interpretation of a triangle hydrograph. 


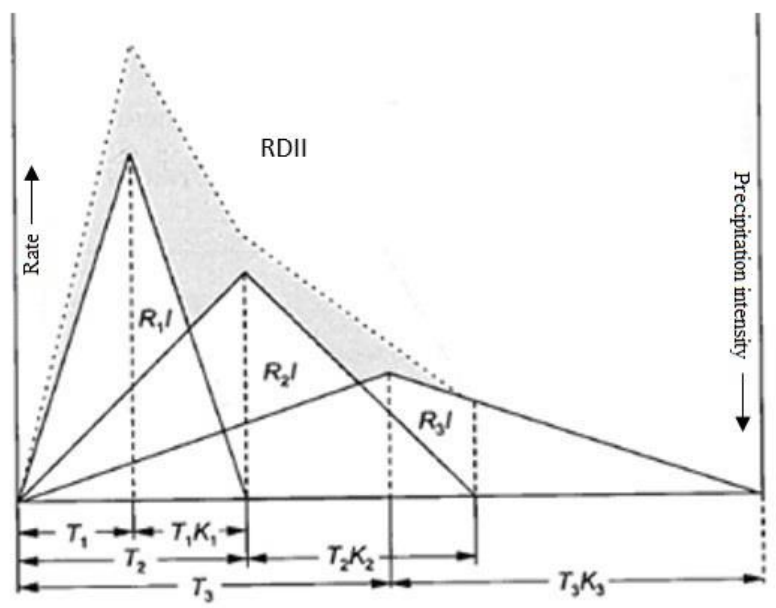

Fig. 1. A triangle hydrograph developed on the basis of the three parameters of surface run-off rate

A hydrograph constructed according to RTK method (RTK hydrograph) consists of three Snider triangles, each of them being represented by the following three parameters: $\mathrm{R}, \mathrm{T}$ and $\mathrm{K}$, which may be used together with the maximal (peak) surface run-off flows obtained on the basis of different calculation methods.

Figure 1 shows an RTK hydrograph, where RDII is the sum of design flows for every unit hydrograph at the moment in question.

The parameters of design flows are determined by the RTK unit hydrograph method according to the following equation:

$$
\frac{1}{2}\left(T_{i}+T_{i} K_{i}\right) Q_{p i}=\frac{R_{i} P A}{3600 \mathrm{~s} / \mathrm{hr}}
$$

where: $T_{i}$ - time before the peak, h; $K_{i}$ - relation between the time and the drop at the peak moment; $Q_{p i}$ - peak flow $\left(f t^{3} / \mathrm{sec}, \mathrm{m}^{3} / \mathrm{sec}\right) ; R_{i}$ - run-off volumetric coefficient; $P$ precipitation amount (ft, $\mathrm{m}) ; A$ - the size of a water catchment area $\left(f t^{2}, m^{2}\right)$.

RDII is a total flow-rate curve designed to determine the storm-water flow rates per hour during rainfalls and it is calculated using the following equations:

if $t<T$, the flow-rate is calculated according to the equation:

$$
Q=Q_{p i} \frac{t}{T_{i}}
$$

if $T_{i} \leq t \leq T_{i} K_{i}+T_{i}$, the flow rate is calculated by the equation:

$$
Q=Q_{p i}\left(1-\frac{t-T_{i}}{T_{i} K_{i}}\right)
$$

where $Q_{p i}$ - the peak flow-rate $\left(\mathrm{ft}^{3} / \mathrm{sec}, \mathrm{m}^{3} / \mathrm{sec}\right) ; T_{i}$ - time before the occurrence of peak flow, h; $K_{i}$ - the relation between time and the drop at the peak moment; $t-$ time since the beginning of precipitation fallout $(\mathrm{h})$.

In accordance with the European legislation, the software for the calculation of surface run-off disposal systems must meet the requirements established by the regulatory document BS EN 752:2008 [7]. This document says that it is necessary to calculate the flow-rates of storm-water run-off taking into account the following factors: design rainfall intensity, the size of watershed area, the size of water-impermeable surfaces, some possible storm-water run-off losses a result of leakage into soil, etc. According to BS EN 752:2008, 
if there are no methods for storm-water run-off rate calculation, and the size of the water catchment area is less than 200 ha, the following equation is used for the calculation of storm-water flow-rate:

$$
Q=C \cdot I \cdot A
$$

where: $\mathrm{Q}$ - storm-water flow-rate, $1 / \mathrm{sec}$; C- run-off coefficient (in the range of 0.0 and 1.0), a dimensionless value;

I - rainfall intensity, $1 /(\mathrm{sec} \cdot \mathrm{ha})$; A- the size of the water catchment area, ha.

In foreign literature $[8,9]$ equation 6 is referred to as a rational method.

Rainfall intensity I in the equation 6 is taken to be maximal on the basis of a statistical analysis of rainfall intensity for the territory in question. It is not difficult to see that the rainfall intensity in equation 6 is a constant value.

In the Russian Federation the calculation of flow-rate in storm-water disposal sewers is carried out according to Construction Regulations SP 32.13330.2012 "Wastewater Disposal Systems. External Networks and Facilities" [10,11] using the method of limiting intensities based on the following relations:

$$
Q_{r}=Z_{\text {mid }} \cdot A^{1.2} \cdot \frac{F}{t_{r}^{1.2 n-0.1}}
$$

where: $z_{\text {mid }}$ - run-off coefficient; $\mathrm{F}$ - the size of water catchment area, ha; $t_{r}$ - time for storm-water travelling to the collection network cross-section in question, taken to be equal to the duration of the rainfall, min; A - design climatic parameter determined according to the equation 8:

$$
A=q_{20} \cdot 20^{n} \cdot\left(1+\frac{\lg P}{\lg m_{r}}\right)^{y}
$$

where: $q_{20}$ - rainfall intensity for the territory in question of 20 minutes duration, in case the period of a one-fold exceeding of the design rainfall intensity $\mathrm{P}=1$ year; $m_{r}-$ the average number of rainfalls per year; $y$ - the power coefficient taken according to the table in Appendix 3 to the "Recommendations for the calculation of the systems for the collection, disposal and treatment of surface run-off from residential territories and industrial sites, and for determining the conditions for this surface run-off disposal into water bodies" [11].

It is not difficult to notice that for the calculation of storm-water flow-rates, Russian regulatory documents $[10,11]$ apply power-law connections, including the relation between the intensity of rainfall, surface run-off flow rate and the time for storm run-off travelling, which is not present in the calculation equation of BS EN 752:2008 standard. This fact may result in considerable disagreements in the determination of diameters for the gravity-glow storm-water drainage networks.

\section{Results}

In order to prove the above-mentioned assumptions, the storm-water rates were determined through the application of the rational method in accordance with the requirements established by BS EN 752:2008 and by the method of limiting intensities according to SP 32.13330.2012. The design case assumed the disposal of surface run-off from three water catchment territories of 0.7 ha total area, these water catchment areas being located along the route of the sewer being designed. The total length of the sewer being designed amounts to 300 meters. The design case also presumed the ingress of concentrated flow-rates into the system amounting to 15 and $5 \mathrm{l} / \mathrm{sec}$ and located at the distance of 100 and 200 meters from the beginning of the sewer route correspondingly. The climatic parameters of Moscow 
and the Moscow Region were used for the calculations. The results of calculations are given in Figures $2-4$.

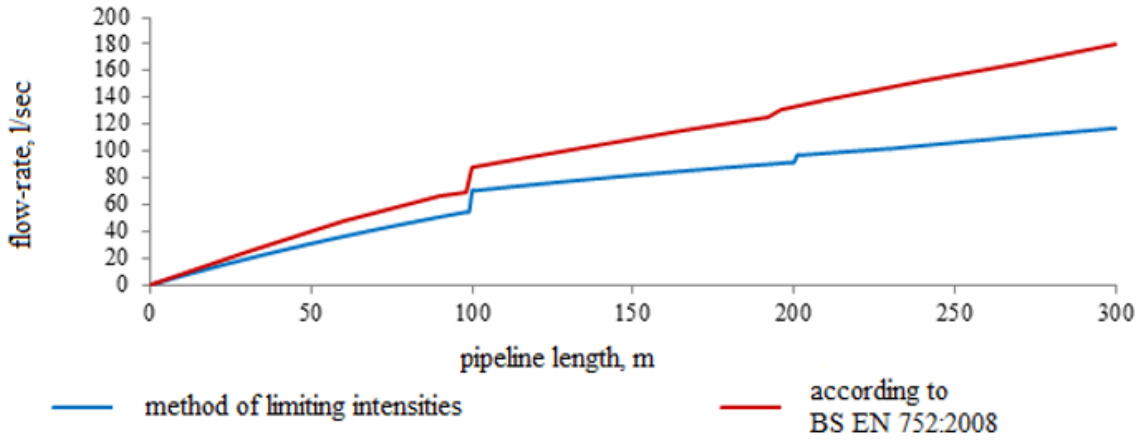

Fig. 2. The results obtained for the calculation of storm-water run-off design flow-rates, according to the rational method (BS EN 752:2008) and the method of limiting intensities (SP 32.13330.2012.)

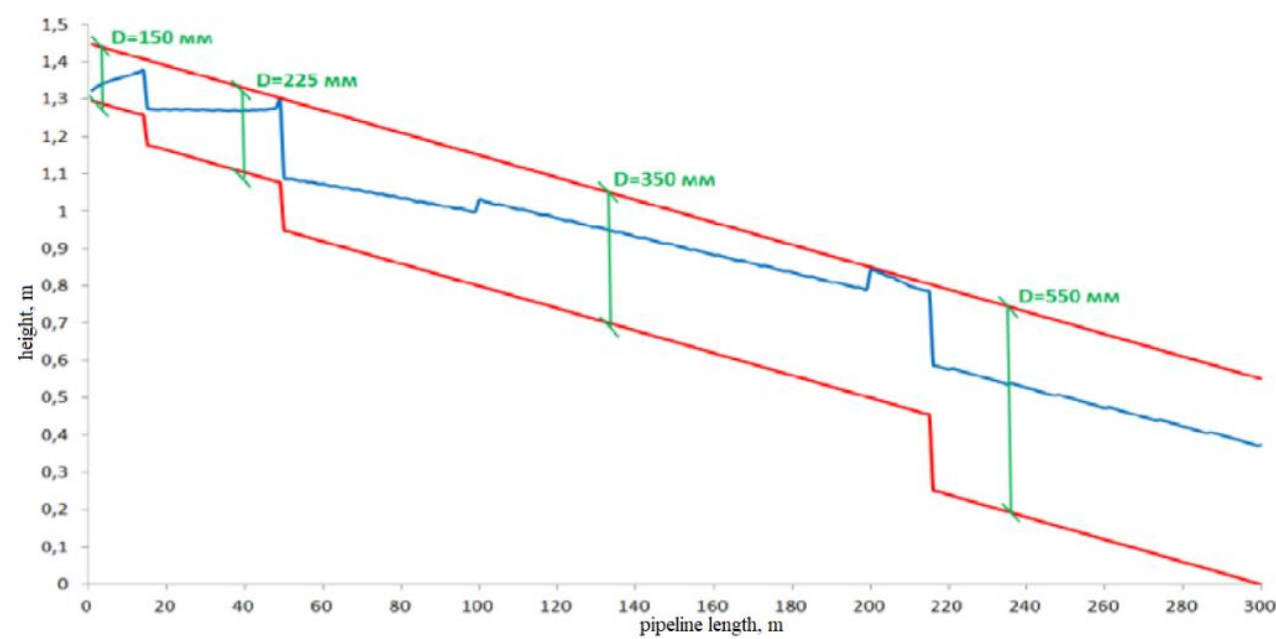

Fig. 3. The longitudinal canal profile calculated using the method of limiting intensities (SP

$32.13330 .2012)$

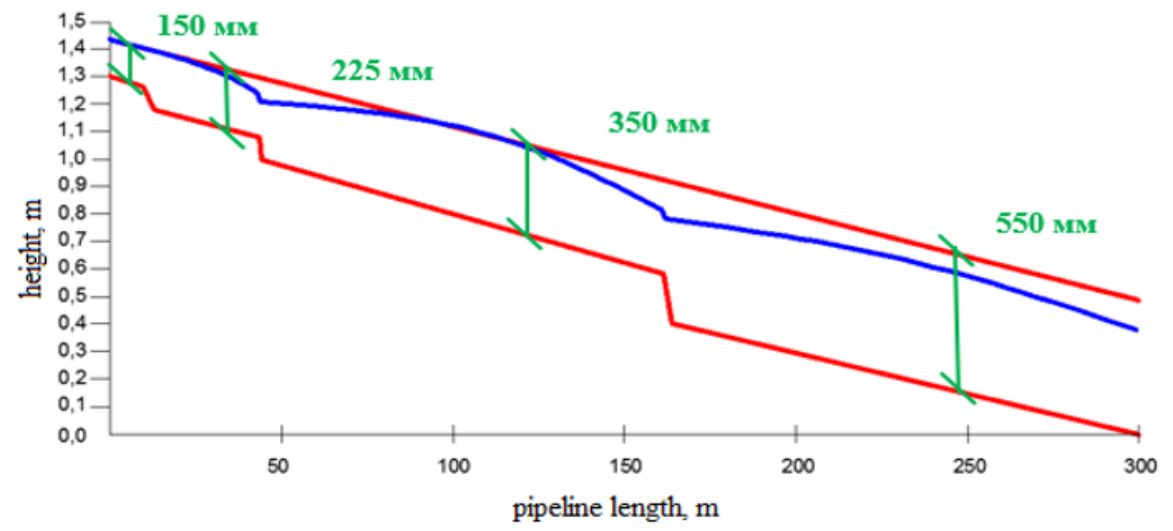

Fig. 4. The longitudinal canal profile calculated according to the rational method (BS EN 752:2008) 
In order to make the above-mentioned hydraulic calculations aimed at determining the diameter of a sewer, "MosvodokanalNIIproject" JSC developed an algorithm using the VBA language. The structure of this algorithm operation is represented by the two units: the unit for calculating the flow of surface run-off from the water catchment area and the unit for the hydraulic calculation of the sewer. The advantage of this algorithm is the fact that it applies the principles of network hydraulic calculation using the method of limiting intensities in accordance with SP 32.13330.2012. Apart from that, the operation of the hydraulic unit for the first time envisaged the possibility for the calculation of oval-type pipes.

Figure 2 makes it clear that the flow-rates calculated according to equation 6 are considerably higher than the flow-rates calculated according to equation 7, as a result of which the diameter of $550 \mathrm{~mm}$ is applied for the canal length of $160 \mathrm{~m}$, unlike the method of limiting intensities - for the length of $220 \mathrm{~m}$, thus the difference is $60 \mathrm{~m}$. It means that the diameters of a gravity-flow storm-water disposal network are oversized as a result of rational method application, resulting, in the long run, in increased cost of its construction.

\section{Developing a run-off hydrograph according to the RTK unit hydrograph method}

A surface run-off hydrograph was calculated and constructed in accordance with the RTK hydrograph method and mathematical relationships (3-5).

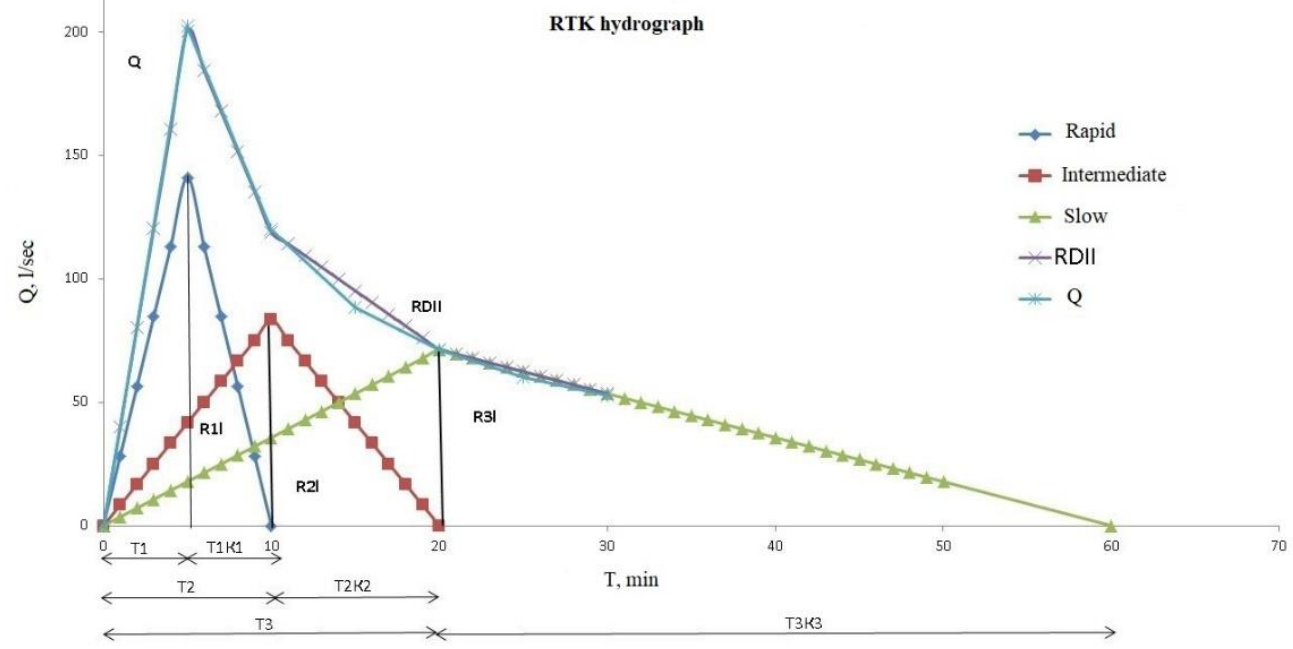

Fig. 5. Run-off hydrograph obtained for the calculation of surface run-off flow-rate

The calculations shown in Figure 5 revealed that it was impossible to use foreign software for the regulatory documents of the Russian Federation, since they are based on different mathematical relationships. Nevertheless, the method of RTK hydrograph that comprises the construction of Snider unit triangles, may be used for the calculation of surface run-off flow-rate.

\section{Conclusions}

1. The analysis of the Russian software used for the calculation of gravity-flow storm-water drainage networks revealed the impossibility of this software application for 
the hydraulic calculations of gravity-flow storm-water drainage networks by the method of limiting intensities, according to valid regulatory and methodological documents.

2. Comparison of the results for the determination of surface run-off flow rates, obtained according to the regulatory document BS EN 752:2008 and according to Russian regulatory and methodological documents, revealed the impossibility to apply the equations of the European standard BS EN 752:2008 for the development of software electronic models for making the hydraulic calculations in accordance with the requirements established by Russian standards.

3. It was found out that it was possible to use the RTK hydrograph method (surface run-off hydrograph) comprising the construction of Snider unit triangles, for the development of electronic models for the hydraulic calculation of storm-water drainage networks.

\section{References}

1. The Resolution of the Russian Federation Government of September 5, 2013, N 782. Concerning the Water Supply and Wastewater Disposal Systems;

2. Official web-site of "ZuLu" Software (2018). URL: https://www.politerm.com/ (access date: 29.08.2018);

3. Official web-site of "City Com" Software URL: http://citycom.ru/citycom/hydrograph/ (access date: 29.08.2018);

4. Official web-site of "ИСИГР" Software URL: http://51.isem.irk.ru/ (access date: 29.08.2018);

5. Official web-site of Bentley Software URL: https://www.bentley.com/ru (access date: 29.08.2018);

6. Official web-site of Mike Urban Software URL: https://www.mikepoweredbydhi.com/ products/mike-urban (access date: 29.08.2018);

7. BS EN 752:2008. External Wastewater Disposal Systems;

8. T.M. Walski, T.E. Barnard, E. Harold, L.V.B. Merritt, N. Walker, B.E. Whitman, Wastewater collection system modeling and design, Bentley Institute Press, (Pennsylvania USA: Exton, 2007), 606;

9. T. Nasrin, H. D. Tran, N. Muttil, Modeling Impact of Extreme Rainfall on Sanitary Sewer System by Predicting Rainfall Derived Infiltration, Inflow, 20th International Congress on Modeling and Simulation, Adelaide, Australia, (1-6 December, 2013),7.

10. Construction Regulations SP 32.13330.2012 Wastewater Disposal. External Networks and Facilities. Updated Version SNiP 2.04.03-85. (with amendment №1, approved 30.12.2015 by the order of the Ministry of Construction of the Russian Federation $\mathrm{N}$ 986/pr);

11. Guidance Manual. Recommendations for the Calculation of Systems for Collection, Disposal, and Treatment of Surface Run-Off from Residential Areas and Industrial Sites and for Determining the Conditions for Surface Run-Off Disposal into Water Bodies. Obligatory Supplement to the Construction Regulations SP 32.13330.2012. Wastewater Disposal. External Networks and Facilities (with amendment 1, approved 30.12.2015 by the Order of the Ministry of Construction N 986/pr);

12. Regional Construction Standards TSN 40-302-2001, Moscow Region. Storm Water Drainage System. Organization of Surface Run-Off Collection, Treatment and Disposal. Moscow Region. 2001; Appendix 1. 